\title{
Food intolerance and food allergy in children: a review of 68 cases
}

\author{
A M B MINFORD, A MACDONALD, AND J M LITTLEWOOD \\ St James's University Hospital, Department of Paediatrics, Leeds
}

SUMMARY The clinical and laboratory features of 68 children with food intolerance or food allergy are reviewed. Young children were affected the most with $79 \%$ first experiencing symptoms before age 1 year. Forty-eight $(70 \%)$ children presented with gastrointestinal symptoms (vomiting, diarrhoea, colic, abdominal pain, failure to thrive), $16(24 \%)$ children with skin manifestations (eczema, urticaria, angioneurotic oedema, other rashes), and $4(6 \%)$ children with wheeze. Twenty-one children had failed to thrive before diagnosis. A single food (most commonly cows' milk) was concerned in $28(41 \%)$ cases. Forty (59\%) children had multiple food intolerance or allergy; eggs, cows' milk, and wheat were the most common. Diagnosis was based on observing the effect of food withdrawal and of subsequent rechallenge. In many children food withdrawal will mean the use of an elimination diet which requires careful supervision by a dietician. Laboratory investigations were often unhelpful in suggesting or confirming the diagnosis.

The frequency with which symptoms in children are attributed to a food varies greatly among paediatricians. While none would doubt the existence of food allergy as a distinct entity, a certain amount of scepticism exists regarding its frequency. The limited diagnostic contribution of laboratory investigations is probably the major factor responsible for this scepticism. Other sources of difficulty are occasional overworking of the diagnosis to explain a large variety of symptoms, the often transient nature of the condition, and confusion over definition of terms. We have followed the suggestion of Lessof et al. ${ }^{1}$ that the term food allergy should be restricted to clear immediate (within one hour) IgE-dependent reactions. Apart from gastrointestinal disturbance, symptoms should include such features as lip swelling, urticaria, or asthma and diagnosis generally be supported by a positive skin prick test or a radioallergosorbent test (RAST). In the absence of such evidence the less specific diagnosis of 'food intolerance' was preferred. Uncertainty about the prevalence of food allergy and intolerance in children is reflected in the few reported series from the $\mathrm{UK}^{2}$ with the exception of cows' milk intolerance. We therefore felt it would be useful to report our experience of food allergy and food intolerance in children during the 10-year period 1972 to 1981.

\section{Patients}

During the 10-year period, the diagnosis of food allergy or intolerance was considered likely in 121 children referred to one (JML) of us, a general paediatrician with an interest in gastroenterology. Sixty-eight patients (41 boys and 27 girls) were included in the series. Their ages at the time of presentation ranged between 1 month and 11 years.

Diagnostic methods and criteria for inclusion in the series. The patients included had relief of symptoms on withdrawal of the offending food or foods and recurrence of symptoms on at least 3 challenges with that food or those foods. The two exceptions to these criteria were children with severe immediate reactions (urticaria once, angioneurotic oedema twice) to egg ingestion. We did not feel justified in repeating the challenges because of the severity of these symptoms. In the other 66 children food withdrawal took the form of stopping the suspected food or foods (generally milk or eggs in infants) or, more often, took the form of an elimination diet.

For the latter all common food allergens were eliminated from the diet for a period of 2 or 3 weeks. The foods allowed were those thought to be less allergenic (Table 1). If the child's symptoms did not improve within this time, it indicated that factors other than food were contributing to the symptoms 
Table 1 Basic elimination diet

\begin{tabular}{ll}
\hline Foods allowed & Major foods excluded \\
\hline Lamb & Beef, pork, poultry \\
Rice & Wheat, rye, oats, barley, corn \\
Carrots & All other vegetables \\
Pears, peaches, apricots & All other fruits \\
Tea & Coffee, squashes, Oxo, Bovril etc. \\
Sugar (white) & Major colours and preservatives \\
Tomor margarine & Eggs, fish \\
Milk substitute & Milk and dairy products \\
\hline
\end{tabular}

or, rarely, that the elimination diet still contained a food of which the patient was intolerant. ${ }^{3}$ If the symptoms did improve, the patient was challenged with one new food every 6 days, less allergenic foods -for example, potatoes, vegetables, fruit-generally being reintroduced early. If a reaction was produced no other new food was introduced for at least a week or until symptoms were alleviated. If there was any suggestion that a child might react severely to a particular food he was brought into hospital for a carefully monitored challenge under medical supervision. Parents were asked to keep records of food reintroduced and to note any resulting symptoms.

Infants with suspected cows' milk protein intolerance were given a cows' milk-free substitute (soya based milk)* and if necessary cows' milk-free weaning foods. Occasionally, if symptoms did not remit or later recurred on a soya-based milk, an enzymatically hydrolysed casein formula $\dagger$ was substituted. To confirm the diagnosis we used the criteria of Goldman et al. ${ }^{4}$ which are as follows: (1) Symptoms subside after dietary elimination of cows' milk. (2) Symptoms recur within 48 hours after milk challenge. (3) Reactions to 3 such challenges must be positive and last for similar durations with similar clinical features. Cows' milk challenges were carried out in hospital if a severe reaction was considered likely. However, cows' milk was always reintroduced slowly starting with $5 \mathrm{ml}$ added to the milk substitute feed and increasing the amount gradually in subsequent feeds. In the case of infants with severe failure to thrive, challenges were delayed until satisfactory catch-up growth had occurred.

Children with coeliac disease or disaccharide intolerance were not included either in the 68 patients included in the series or in the 53 who were rejected because of failure to satisfy our criteria. Using the criteria of Lessof et al. ${ }^{1}$ we could identify 15 children as having food allergy. Twelve of the 15 children had supportive evidence in the form of positive skin prick tests or the presence of specific IgE antibodies demonstrated by RASTs. In the remaining 53 children considered to have food

* Prosobee, † Nutramigen. intolerance, symptoms occurred between 1 and 24 hours after ingesting the offending food. There was considerable overlap in terms of symptoms and laboratory investigations between the two groups and as the distinction between them was not absolute details of the 68 patients are presented as a whole.

Thirty patients had skin prick tests (Bencard) and a weal of $3 \mathrm{~mm}$ was taken as positive. Total serum IgE was estimated in 56 patients by the paper radioimmunosorbent technique. RAST* was used to detect specific IgE to foods in 60 patients, and results were graded $0-4$; grades of 2 or more were regarded as positive.

Clinical features. Birthweights of the 68 children ranged from 2.19 to 4.85 (mean 3.34 ) $\mathrm{kg}$. Only 2 children, weighing less than $2.5 \mathrm{~kg}$ at birth, were light for gestational age. All 68 children had been born between 37 and 42 weeks' gestation and none had had any major perinatal problem. Forty-three children had been partially or totally breast fed at some time.

The onset of symptoms occurred during the first year of life in $54(79 \%)$ children with $24(35 \%)$ children experiencing symptoms in the first 6 weeks. Symptoms first occurred between 1 and 5 years in 8 $(12 \%)$ children and after 5 years in $6(9 \%)$ children. The interval between onset of symptoms and the time when appropriate clinical action was taken to exclude food allergy or intolerance was shorter than 6 months in 42 children, between 6 and 12 months in 10 children, and longer than 1 year in 16 children.

The symptoms experienced by the 68 children are shown in Table 2 . They were mainly gastrointestinal with vomiting present in just under half the cases. Although 24 babies had prolonged screaming or colic, this was the sole symptom in only two. Skin

Table 2 Symptoms experienced by the 68 children

\begin{tabular}{lll}
\hline Symptom & \multicolumn{2}{l}{ Children } \\
\cline { 2 - 3 } & No & $(\%)$ \\
\hline Vomiting & 32 & $(47)$ \\
Diarrhoea & 28 & $(41)$ \\
Crying/colic & 24 & $(35)$ \\
Failure to thrive & 21 & $(31)$ \\
Eczema & 15 & $(22)$ \\
Abdominal pain & 13 & $(19)$ \\
Wheeze & 13 & $(19)$ \\
Urticaria & 12 & $(18)$ \\
Other rashes & 9 & $(13)$ \\
Mood alteration & 8 & $(12)$ \\
Angioneurotic oedema & 7 & $(10)$ \\
Flatulence & 7 & $(10)$ \\
Abdominal distension & 5 & $(7)$ \\
Steatorrhoea & 2 & $(3)$ \\
\hline
\end{tabular}

* Pharmacia Diagnostics, although a few antigens were prepared by our Department of Immunology. 
involvement, the second most common symptom, was present in 36 children, who were often clearly atopic. Mood alteration, related to food, never occurred alone. Wheeze was the sole symptom in only 2 children. Two children had immediate reactions to skin contact with the offending food. The principal presenting features were again mainly gastrointestinal (Table 3) with skin involvement taking second place.

Among the 68 patients with food allergy or intolerance, four groups of patients could be identified (Table 4). The largest group, group 1, included 20 infants with cows' milk intolerance. The 23 obviously atopic children in group 2 included 15 who had gastrointestinal symptoms as well. The distinction between groups 1 and 2 is not absolute as it is possible that an infant in group 1 may later qualify for group 2 . Only $9(13 \%)$ were older children with chronic gastrointestinal symptoms particularly recurrent abdominal pain or chronic diarrhoea.

\section{Case reports.}

\section{Group 1}

This 23-month old boy was referred with diarrhoea, recurrent perianal and perioral redness, and soreness from age 3 months. On examination he was thin (length 90th centile, weight 50th centile) and had red excoriated lesions around his mouth and anus.

Table 3 Main presenting symptoms in 68 children

\begin{tabular}{lll}
\hline Symptom & \multicolumn{2}{l}{ Children } \\
\cline { 2 - 3 } & No & $(\%)$ \\
\hline Vomiting & 13 & $(19)$ \\
Diarrhoea & 12 & $(18)$ \\
Crying/colic & 12 & $(18)$ \\
Urticaria \pm angioneurotic & & \\
$\quad$ oedema (often eczema & 10 & $(15)$ \\
$\quad$ as well) & 8 & $(12)$ \\
Abdominal pain & 5 & $(7)$ \\
Eczema & 4 & $(6)$ \\
Wheeze & 3 & $(4)$ \\
Failure to thrive & 1 & $(1)$ \\
Other rashes & & \\
\hline
\end{tabular}

Table 4 Groups of patients with food allergy or intolerance

\begin{tabular}{llll}
\hline Group & Type of patient & Number & $\%$ \\
\hline 1 & $\begin{array}{l}\text { Mainly gastrointestinal symptoms } \\
\text { in children under 2 years. No } \\
\text { atopic symptoms } \\
\text { Obviously allergic individual. } \\
\quad \text { Atopy - eczema, asthma } \pm \text { urticaria } \\
\text { Chronic or recurrent gastro- } \\
\text { intestinal symptoms in older } \\
\text { children }\end{array}$ & 32 & 47 \\
\hline $\begin{array}{l}\text { Obvious acute skin reactions. } \\
\text { Acute urticaria. No other atopic } \\
\text { features }\end{array}$ & 4 & 13 \\
\hline
\end{tabular}

Jejunal biopsy was normal. Skin prick tests and RASTs to a number of allergens including wheat were negative. $\mathrm{He}$ responded to an elimination diet but relapsed when wheat was reintroduced although he could tolerate all other foods. Profuse diarrhoea recurred on subsequent challenges.

\section{Group 2}

This boy developed eczema, recurrent cough, and vomiting when cows' milk and solids were introduced at $4 \frac{1}{2}$ months. When seen at $8 \frac{1}{2}$ months, he was failing to thrive (Figure) and had severe eczema. He had strongly positive skin prick tests to eggs and milk and grade 4 positive RASTs to milk, eggs, and wheat. He responded strikingly to an elimination diet, and subsequent challenges confirmed allergy to eggs, wheat, and cows' milk. He thrived during the next 4 months but at 17 months his eczema recurred and weight gain had become static. Serum total IgE was $1160 \mathrm{U} / \mathrm{ml}$. RASTs to house dust mite, grass pollen, soya flour, lamb, chicken, potato, and tomato were positive in addition to milk, eggs, and wheat. He remains a difficult case to manage.

Group 3

This 12-year-old girl, thought to have the irritable bowel syndrome, was referred with a 4-year history

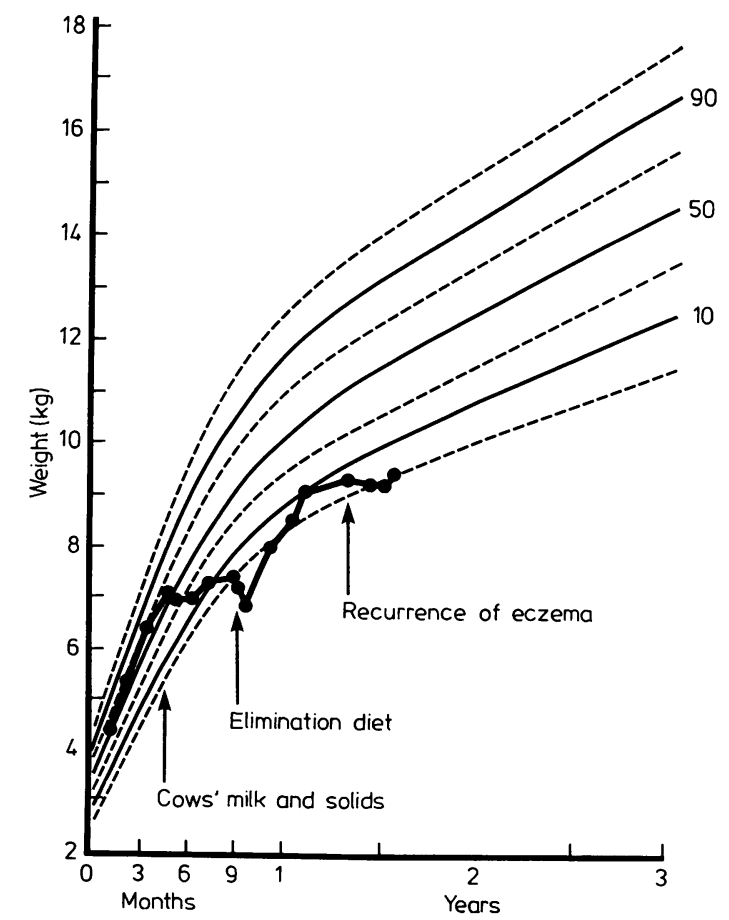

Figure Weight chart for a child (group 2) with multiple food allergies. 
of abdominal pain, intermittent vomiting, and diarrhoea. Her growth was satisfactory. Jejunal biopsy was normal. Her serum IgA level of $0.67 \mathrm{~g} / 1$ was below the normal range for age. RASTs for specific IgE to many foods including potato were negative. She responded to an elimination diet but relapsed when potato was reintroduced. She tolerated all other foods. When last seen 2 years later she was well on a potato-free diet but still reacting to challenges with the same symptoms.

\section{Group 4}

This child was well until he first ingested egg at age 6 months. While eating an egg, his tongue became swollen and he began to choke. Within an hour he had periorbital oedema and several hours later had generalised urticaria. Six weeks later he had an identical reaction with egg custard. Egg RAST was positive but total IgE was normal. His symptoms have not recurred on an egg-free diet.

Other allergies. Evidence for allergies other than to food was present in 10 children, all of whom belonged to the atopic group. In each case, the allergies were thought likely on clinical grounds and, with the exception of 2 children who were allergic to penicillin, were confirmed by RASTs or skin prick tests. The other allergens were house dust mite (8 cases), pollen (6 cases), dog (1 case), and cat (1 case).

Family history. A history of atopy or suspected food intolerance was present in the siblings or parents of $28(42 \%)$ children. Eighteen children had a family history of atopy; 8 had a family history of suspected food intolerance and 2 a family history of atopy and food intolerance.

Foods involved. Only one food was implicated in 28 $(41 \%)$ cases, the majority (20 cases) being infants with cows' milk intolerance. Two children who were intolerant only of wheat had normal jejunal biopsies. The other single foods were egg (4 cases), potato ( 1 case), and coffee ( 1 case). Forty $(59 \%)$ children were intolerant of or allergic to more than one food (Table 5). Eggs, cows' milk, and wheat were by far the most common offending foods. Twenty-three children were intolerant of more than three foods. Secondary development of soy protein intolerance occurred in only 1 child.

Investigations. Thirty-eight children had RAST estimations to cows' milk, eggs, and wheat only and 2 to cows' milk only. Twenty children, including 16 with multiple food allergy or intolerance, had more extensive RASTs to additional foods. The numbers of positive milk, egg, and wheat RASTs in children clinically intolerant of these foods are shown in
Table 5 Foods involved in multiple food allergy/ intolerance

\begin{tabular}{ll}
\hline Food & Number of cases \\
\hline Eggs & 32 \\
Milk & 28 \\
Wheat & 16 \\
Chicken & 10 \\
Fish & 8 \\
Pork & 7 \\
Cheese & 6 \\
Peas & 5 \\
Apples & 5 \\
Dyes and colouring & 5 \\
Preservatives & 4 \\
Beef & 4 \\
Butter & 4 \\
Chocolate & 4 \\
Cabbage, bananas, strawberries, tomatoes, & 3 each \\
pasta & 2 each \\
Oranges, baked beans, jelly, onions, nuts & 1 each \\
Soya, porridge, rabbit, rye, raisins, potatoes & \\
\hline
\end{tabular}

Table 6. For all 3 foods, RASTs were more likely to be positive in group 2 than in group 1 patients. No positive RAST was found in group 3 patients. There were too few in group 4 to comment on. Egg RASTs were more likely to be positive than milk RASTs. Only 5 of the 20 children who had more extensive RASTs had positive results to at least one food of which they were clinically intolerant. Four children had 10 positive RASTs to foods which did not produce symptoms (false-positives). The number of patients who had total IgE levels more than 1 standard deviation above the mean is also shown in Table 6. This occurred most often in the atopic group.

Twenty-six patients had skin prick tests to cows' milk, egg, and wheat. More extensive skin prick tests were carried out in 4 children. Thirteen positive skin prick tests were recorded in 10 children.

Seventeen of the 56 patients who had differential white cell count estimations had eosinophil counts

Table 6 RASTs to milk, egg, and wheat in patients clinically intolerant of these foods and total IgE levels

\begin{tabular}{|c|c|c|c|c|}
\hline & $\begin{array}{l}\text { Group } \\
1\end{array}$ & $\begin{array}{l}\text { Group } \\
2\end{array}$ & $\begin{array}{l}\text { Group } \\
3\end{array}$ & $\begin{array}{l}\text { Group } \\
4\end{array}$ \\
\hline $\begin{array}{l}\text { Number of milk RASTs in } \\
\text { milk-intolerant patients }\end{array}$ & 22 & 15 & 4 & 1 \\
\hline $\begin{array}{l}\text { Number positive } \\
\% \text { positive }\end{array}$ & $\begin{array}{l}3 \\
14 \%\end{array}$ & $\begin{array}{l}6 \\
40 \%\end{array}$ & $\begin{array}{l}\mathbf{0} \\
\mathbf{0}\end{array}$ & 1 \\
\hline $\begin{array}{l}\text { Number of egg RASTs in } \\
\text { egg-intolerant patients }\end{array}$ & 9 & $14^{\prime 2}$ & 3 & 3 \\
\hline $\begin{array}{l}\text { Number positive } \\
\% \text { positive }\end{array}$ & $33 \%$ & $\begin{array}{l}9 \\
64 \%\end{array}$ & $\begin{array}{l}\mathbf{0} \\
\mathbf{0}\end{array}$ & 1 \\
\hline $\begin{array}{l}\text { Number of wheat RASTs in } \\
\text { wheat-intolerant patients }\end{array}$ & 10 & 6 & 1 & 0 \\
\hline Number positive & 0 & 4 & 0 & 0 \\
\hline $\begin{array}{l}\text { Number of patients who had } \\
\text { PRIST }\end{array}$ & 27 & 17 & 9 & 3 \\
\hline $\begin{array}{l}\text { Number with IgE level }>1 \text { SD } \\
\text { above mean }\end{array}$ & 6 & 12 & 4 & 1 \\
\hline $\begin{array}{l}\% \text { with IgE level }>1 \text { SD } \\
\text { above mean }\end{array}$ & $22 \%$ & $70 \%$ & & \\
\hline
\end{tabular}

RAST = radioallergosorbent test,

PRIST = paper radioimmunosorbent technique. 
greater than 250 eosinophils per $\mathrm{mm}^{3}$. Nine of these children were in group 2. Low IgA levels were found in 7 of the 40 children who had serum immunoglobulin estimations. Fifteen children had sweat tests, all of which were normal. No abnormality was found in 12 of the 19 children who had barium examinations of the upper gastrointestinal tract. Five infants had significant gastro-oesophageal reflux, 2 with a demonstrable hiatal hernia. Pylorospasm was demonstrated in 2 infants, one of whom previously had pyloromyotomy. Jejunal biposies were carried out in 16 children, the indications being failure to thrive, diarrhoea, steatorrhoea, and clinical intolerance of wheat. Jejunal mucosa was histologically normal in 14 children. Partial villous atrophy was found in 2 infants with cows' milk protein intolerance.

Other medical conditions. These included cystinuria and congenital myopathy ( 2 sisters), epilepsy (1 case), cleft palate (1 case), microphthalmia (1 case), and hyperactivity unrelated to food ( 2 cases). Seven children with cows' milk intolerance had structural abnormalities of the upper gastrointestinal tract. After pyloromyotomies for pyloric stenosis, 2 children continued to vomit until cows' milk was withdrawn. One child with hiatal hernia and 3 with gastro-oesophageal reflux continued to vomit despite anti reflux measure until cows' milk was stopped. The other child with hiatal hernia presented with vomiting and weight loss which initially responded to Prosobee and a cows' milk-free diet. After recurrence of vomiting at 7 months, hiatal hernia was diagnosed on barium swallow. Despite appropriate medical management and eventually surgical repair at 11 months, vomiting persisted and he lost weight. When secondary soy protein intolerance was considered possible and Prosobee changed to Nutramigen at 13 months, vomiting ceased and he gained weight. Between 17 and 22 months his mother repeatedly failed to comply with the diet and vomiting recurred. When he was admitted at 22 months because of static weight gain, vomiting ceased, and he quickly gained weight.

Management. Twenty infants were managed with a cows' milk-free diet and 7 children with an egg and cows' milk-free diet. Thirty-one children were given an elimination diet followed by a restricted diet avoiding particular foods. None developed nutritional deficiencies although a few required calcium supplements. Eight children were managed by avoiding a single offending food other than cows' milk. In the case of 2 children with multiple food intolerance, the offending foods were easily identified without an elimination diet and management consisted of avoiding these foods. Of 15 children who received oral sodium cromoglycate either because of incomplete relief of symptoms or the desire for a more liberal diet, 7 derived benefit.

Outcome. At the time of writing, 18 patients have recovered and are on a normal unrestricted diet. A further 13 patients were well when last seen and have been referred back to their general practitioners with only slight dietary modifications. Thirty-six children are still clinically intolerant of at least one food and are still being followed up by us. One patient has been lost to follow up. Only one child (group 2) remains a difficult case to manage.

\section{Discussion}

The 68 children reviewed are a representative group of patients with food allergy or intolerance who had symptoms of sufficient severity to warrant hospital referral. They may not be entirely representative of food allergy and food intolerance in the community as a whole. It is likely that many other children have acute reactions - such as urticaria or abdominal symptoms - after ingestion of one food or a limited number of foods but are managed successfully at home simply by avoiding the particular food. It is evident from this review that food allergy and intolerance predominantly affect very young children. It is possible that certain conditions such as transient IgA deficiency ${ }^{5}$ and intestinal infection ${ }^{6}$ occurring in the first month of life make young children particularly vulnerable. It has been suggested that breast feeding offers a protective effect ${ }^{7}$ but unfortunately it was impossible in this retrospective review accurately to document the incidence of exclusive breast feeding. It is of interest that none of the 68 children had been born preterm. One would have thought that preterm babies might be more likely to develop food allergy or intolerance possibly because of a deficient immune system or increased antigen absorption. ${ }^{8}$ However, recent work in infants intolerant of cows' milk suggests that large amounts of antigen, such as are absorbed during the neonatal period by the cows' milk fed infant, suppress the IgE response while low-dose exposure enhances it. ${ }^{9}$ It may be that in preterm babies increased allergen absorption 'swamps' IgE production mechanisms.

The most common type of patient was a child, younger than 2 years, with mainly gastrointestinal symptoms-such as vomiting, screaming episodes, diarrhoea, and failure to thrive. However, this may be a reflection of the referral pattern to a paediatric outpatient clinic with a gastroenterological interest. Total IgE levels in this group were likely to be normal and RASTs were much less likely to be positive than in group 2 patients who were obviously allergic atopic individuals. Older children with 
chronic diarrhoea or recurrent abdominal pain comprised only $13 \%$ of the total and it is likely that food allergy or intolerance occurs in only a very small minority of children presenting with recurrent abdominal pain. The few children referred with acute urticarial reactions with or without angioneurotic oedema probably does not reflect the true incidence of such children in the community as some may be referred to dermatology outpatient clinics.

The major foods were cows' milk, egg, and wheat which is similar to the findings recorded in adult series. ${ }^{1}$ However in adults, nuts, peanuts, fish, and shellfish are more often responsible. This may simply reflect the different dietary habits of adults.

As an index of the severity of the manifestations of food allergy and intolerance, we would comment on the number of children (21) who were failing to thrive and on the extent of investigations performed - such as sweat tests and jejunal biopsies. Just under one-third of patients had illness of sufficient severity to warrant these more extensive investigations. Although illness in the remaining two-thirds was not generally life-threatening, many of the symptoms were a source of considerable chronic discomfort and parental anxiety.

We were impressed by the number (24) of young babies with cows' milk intolerance who had persistent screaming or colic, although this was the only symptom in two. Infantile colic as a symptom of cows' milk intolerance has been disputed in the past $^{1011}$ but as far as we are aware there are no controlled studies into the relationship: such a study would now seem to be indicated. It is interesting that 7 babies with cows' milk intolerance had structural abnormalities. It is important to consider the possibility of cows' milk intolerance in infants who continue to vomit after treatment of hiatal hernia or after Ramstedt's procedure. In one, surgical repair of the hiatal hernia might have been avoided had the possibility of soy protein intolerance been considered earlier.

We believe that food allergy and intolerance are under-diagnosed. In a significant number of cases laboratory investigations do not help. The laboratory test that was most consistently helpful in supporting the diagnosis was the detection of egg-specific IgE by the RAST in children with clinical egg allergy. In most children with multiple food intolerances, extended RASTs to foods other than egg, milk, and wheat were seldom helpful. Considering the large variety of foods, this is hardly surprising. We have carried out skin prick tests less often than RASTs and often found them to be unhelpful. The mainstay of diagnosis, allergen withdrawal followed by at least 3 positive challenges, often necessitates the use of the elimination diet as a diagnostic tool. It is important to carry out a proper trial with an elimination diet rather than attempt to withdraw individual foods unless there is a clear suggestion from the history that only one or two foods are responsible. Use of the elimination diet and the subsequent reintroduction of more allergenic foods requires considerable skill and supervision by a dietician experienced in the management of food allergy and food intolerance in children. The duration of an elimination diet should not exceed 3 weeks as more prolonged use may result in inadequate calorie intake and other nutritional deficiencies. ${ }^{12}$ Continuing supervision by the dietician during treatment ensures that nutrition is adequate. Unless the diagnosis of food intolerance is considered and either confirmed or excluded, the condition will be missed which will lead to a great deal of unnecessary suffering and anxiety.

We thank Mrs L Tremayne and Miss B R Rodgers for typing the manuscript.

\section{References}

1 Lessof M H, Wraith D G, Merrett T G, Merrett J, Buisseret $P$ D. Food allergy and intolerance in 100 patients-local and systemic effects. $Q J$ Med 1980; 195: 259-71.

2 Syme J. Investigation and treatment of multiple intestinal food allergy in childhood. In: Pepys J, Edwards A M, eds. The mast cell. Tunbridge Wells: Pitman Medical, 1979.

3 Francis D E M. Dietary management. In: Proceedings of the First Food Allergy Workshop, Haslemere, Surrey, 20-23 January 1980. Oxford: Medical Education Services, 1980: 85-94.

4 Goldman A S, Anderson D W, Jr, Sellers W A, Saperstein S, Kniker W T, Halpern S R. Milk allergy. I. Oral challenge with milk and isolated milk proteins in allergic children. Pediatrics $1963 ; 32$ : 425-43.

5 Taylor B, Norman A P, Orgel H A, Stokes C R, Turner M W, Soothill J F. Transient IgA deficiency and pathogenesis of infantile atopy. Lancet 1973; ii: 111-3.

6 Harrison M, Kilby A, Walker-Smith J A, France N E, Wood C B S. Cows' milk protein intolerance: a possible association with gastroenteritis, lactose intolerance, and IgA deficiency. Br Med J 1976; i: 1501-4.

7 Matthew D J, Taylor B, Norman A P, Turner M W, Soothill J F. Prevention of eczema. Lancet 1977; i: 321-4.

8 Roberton D M, Paganelli R, Dinwiddie R, Levinsky R J. Milk antigen absorption in the preterm and term neonate. Arch Dis Child 1982; 57: 369-72.

9 Firer M A, Hosking C S, Hill D J. Effect of antigen load on development of milk antibodies in infants allergic to milk. Br Med J 1981; 283: 693-6.

10 Illingworth R S. Three month colic. Arch Dis Child 1954; 29: $165-74$.

11 Liebman W M. Infantile colic. Association with lactose and milk intolerance. $J A M A 1981 ; 245: 732-3$.

12 Lloyd-Still J D. Chronic diarrhea of childhood and the misuse of elimination diets. J Pediatr 1979; 95: 10-3.

Correspondence to Dr J M Littlewood, Department of Paediatrics, St James's University Hospital, Beckett Street, Leeds LS9 7TF.

Received 17 June 1982 